\title{
Blending Cooking Oil Biodiesel with Petroleum Diesel: A Comparative Performance Test on a Variable IC Engine
}

\author{
Clever Ketlogetswe, Jerekias Gandure
}

University of Botswana, Mechanical Engineering Department, Gaborone, Botswana

Email: ketloget@mopipi.ub.bw

Received February 28 ${ }^{\text {th }}$, 2011; Revised April 11 ${ }^{\text {th }}$, 2011; accepted April 15 ${ }^{\text {th }}, 2011$.

\begin{abstract}
Research in biodiesel production has been motivated by several reasons including consistant increase in prices of petroleum diesel, environmental advantages, security of fuel supply, and employment creation. This paper presents a review of one alternative technological method that can be used to produce this fuel. Biodiesel from used cooking oil was produced by alkali catalyzed transesterification process. Performance of internal combustion engine using this biodiesel blended with petroleum diesel in various blending ratios was performed. The engine performance studies were conducted on a variable compression engine test rig with automatic data acquisition set up. Parameters such as brake power, torque and fuel consumption were measured at different loads for pure petroleum diesel, pure biodiesel and different combinations of the dual fuel. The test results indicate that the performance of the engine is comparable for all the fuel mixtures under review.
\end{abstract}

Keywords: Engine Performance, Biodiesel, Blending

\section{Introduction}

Botswana imports all of its petroleum products and this conjures several questions, the primary of which involves energy security and sustainable access to energy resources among the citizens of the country. The situation has stimulated government interest in developing biofuels industry in Botswana [1], with animal fat and energy crops such as jatropha oil as target feedstocks. The anticipated rapid development of bio-energy sector in Botswana is likely to stimulate more research activities on bio-energy, particularly on issues such as engine performance and emission levels generated from the combustion of different blending mixtures of pure petroleum-based diesel and biodiesel fuels produced from different feed stocks. Several authors [2-4] have carried investigations on the levels of air pollutant emissions using biodiesel produced from different feedstocks. McCormick [2] used biodiesel produced from a variety of feedstocks as well as pure (technical grade) fatty acid methyl and ethyl esters for emission performance in an IC engine. Ramadhas [3] used vegetable oils as IC engine fuels to investigate emission performance, while Rakopoulos [4] investigated emi- ssion performance of IC engine using blends of pure diesel fuels with bio-diesel produced from sunflower or cottonseed oils derived from Greek feedstock. Their overall results indicate that emission of carbon monoxide, particulate matter and polycyclic aromatic hydrocarbons are reduced by using biodiesel compared to the use of pure petroleum-based diesel.

Other advantages of biodiesel include that its physical and chemical properties are very similar to petroleum based diesel fuel in terms of operation in compression ignition engines (diesel engines). Therefore, biodiesel can be used in diesel engines without expensive alterations to the engine or fuel system. Biodiesel is also biodegradable, non-toxic and essentially free of sulphur and aromatics, making it safer to handle and transport. Biodiesel runs in any conventional, unmodified diesel engine, has improved lubricity and high cetane number. The best advantage is the fact that biodiesel is a renewable fuel source, while petroleum fuel is limited. This alone will be the reason for its ever increasing popularity.

This paper discusses a systematic experimental study on comparative analysis of engine brake power, engine torque and specific fuel consumption on a variable com- 
pression ratio IC engine using different blending mixtures of biodiesel produced from used cooking oil and pure petroleum-based diesel.

\section{Materials}

According to the European Union (EU) Directive [5], biodiesel is defined as a methyl ester produced from vegetable or animal oil of diesel quality. Zhang [6] and Luis Fernando Bautista [7] reported that the most common method used to produce biodiesel is to transesterify triacylglycerols in vegetable oil or animal fats with an alcohol in the presence of alkali or acid catalyst. The same authors further pointed out that methanol is the commonly used alcohol in this process, due in part to its low cost. The products are fatty acid methyl esters (biodiesel) and glycerine (by-product). In this work, the fatty acid methyl esters from waste cooking oil processed by a local company, Biodiesel Botswana (Pty) Ltd, was blended with petroleum-based diesel in different mixtures and used to perform experimental study on the effects of engine load on brake power, engine torque and fuel specific consumption. Usually the level of free fatty acids in waste cooking oil is high (greater than $2 \mathrm{wt} \%$ ). A pretreatment step to reduce the free fatty acid content through an esterification reaction with methanol in the presence of sulfuric acid catalyst was done in the processing of biodiesel used in this study. After such a treatment, the oil phase, having a low level of free fatty acids was subjected to the alkali-catalyzed transesterification. The quality of biodiesel was affirmed by Biodiesel Botswana (Pty) Ltd's quality control laboratory, which operates in line with international standards.

\section{Description of Apparatus (Test Rig)}

The TD43F engine test rig was used to perform the systematic experimental study. The test rig is water cooled, four-stroke diesel engine that is directly coupled to an electrical dynamometer. In addition to the conventional engine design, the engine incorporates variable compression design feature which allows the compression ratio to be varied between $5: 1$ to $18: 1$. The engine is designed to use petrol, diesel fuel and propane or natural gas. The variation of compression ratio is achieved by moving the top half of the engine relative to the crankcase. To prevent mechanical damage caused by setting compression ratio outside the design range, two preset stops are incorporated in engine design. A micrometer is used to measure the movement of the cyclinder during the compression ratio adjustment process. The test rig is coupled to the automatic data acquisition software package through a 15-pole sub-D PC connecting box. The system displays and captures data from the TD43 instrumentation in real time.

\subsection{Experimental Procedure}

Prior to the data recording, the compression ratio was set to the desired level and the engine speed was set to a maximum speed of 2500 revs/minute at full throttle and the engine allowed to run for 10 minutes to reach the operating conditions. After the engine temperature had stabilised, the first sets of readings for brake power, engine torque and specific fuel consumption at the maximum speed of $2500 \mathrm{revs} / \mathrm{min}$ were recorded. The dynamometer load was then increased by adjusting the load current control mechanism until the engine speed reduced by steps of $250 \mathrm{revs} / \mathrm{min}$ to a minimum value of approximately 1000. For each step the data for brake power, engine torque and specific fuel consumption were recorded automatically onto a PC using data acquisition provided by the engine manufacturer. The captured data was then processed as presented in Figures 1-3.

\section{Results and Discussion}

A range of fuel mixtures were burned in a systematic study of performance of an IC engine. These mixtures are defined in Table 1 and were tested under two different compression ratios namely 12 and 17 .

The experimental data were collected as discussed earlier, leading to the results presented in Figures 1-3. In addition to the fuel mixture, petroleum diesel fuel and biodiesel were burned separately so as to establish engine performance during their combustion processes. For simplicity, only a sample of the results obtained from these experiments have been presented and discussed in this section. This enables the main findings of the study to be identified and explained.

Typical results for the variations of the brake power, engine torque and specific fuel consumption during the combustion processes for each of the different mixtures are shown in Figures 1-3. Figure 1 shows the effect of engine load and compression ratio on engine torque for different fuels. Figure 2 depicts the effect of increase in load and compression ratio on brake power for the same fuels, while Figure 3 demonstrate the effect of increase in engine load and compression ratio on specific fuel consumption for the same types of fuels.

Table 1. Composition of fuel mixtures tested.

\begin{tabular}{ccc}
\hline Fuel mixture & $\begin{array}{c}\text { Percent diesel } \\
\text { (volume) }\end{array}$ & $\begin{array}{c}\text { Percent biodiesel } \\
\text { (volume) }\end{array}$ \\
\hline 1 & 100 & 0 \\
2 & 0 & 100 \\
3 & 50 & 50 \\
4 & 70 & 30 \\
\hline
\end{tabular}




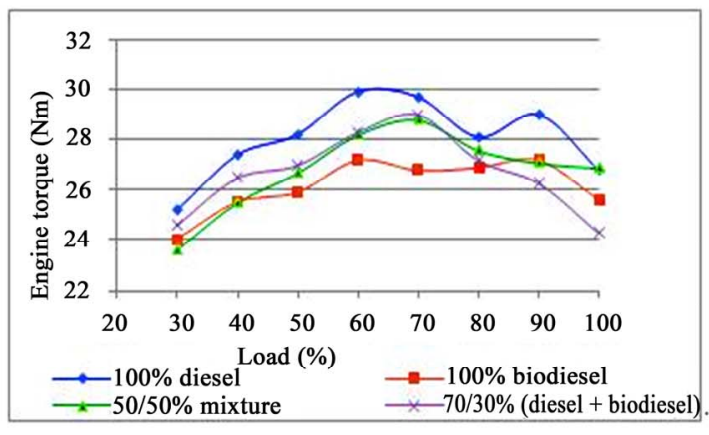

(a)

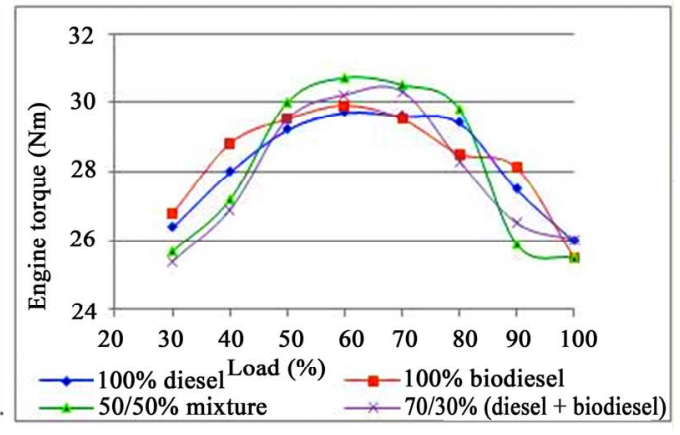

(b)

Figure 1. Engine torque for range of mixtures at selected compression ratios. (a) Compression ratio 12; (b) Compression ratio 17.

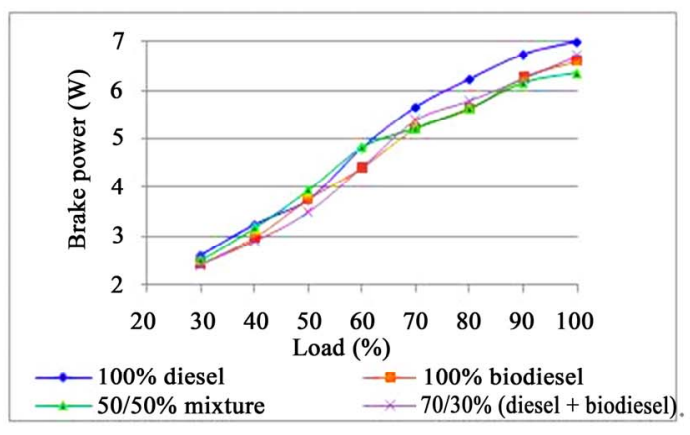

(a)

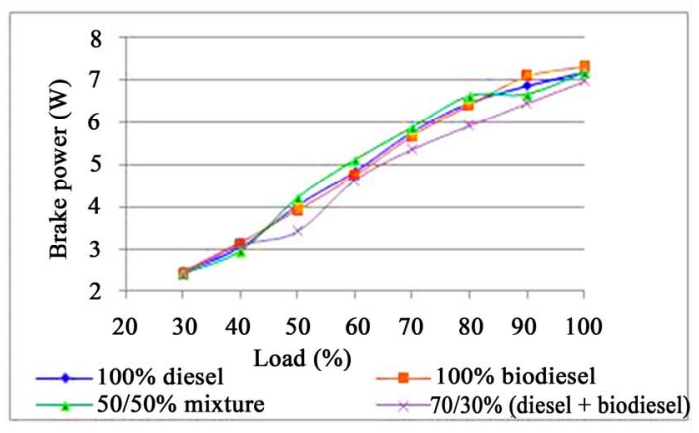

(b)

Figure 2. Engine brake power for range of mixtures at selected compression ratios. (a) Compression ratio 12; (b) Compression ratio 17.

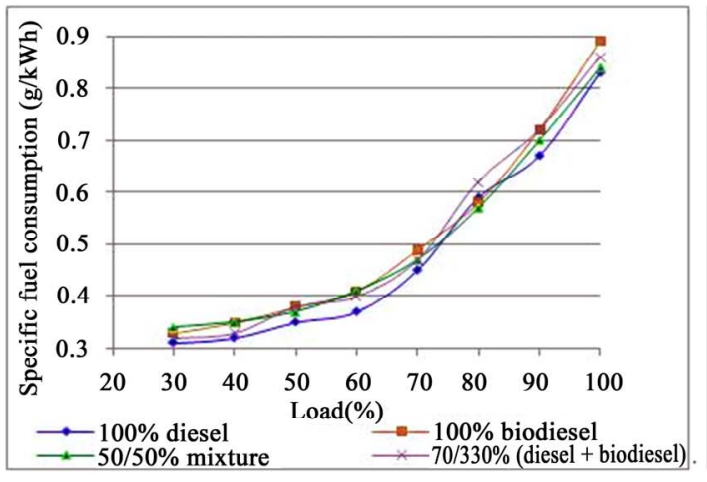

(a)

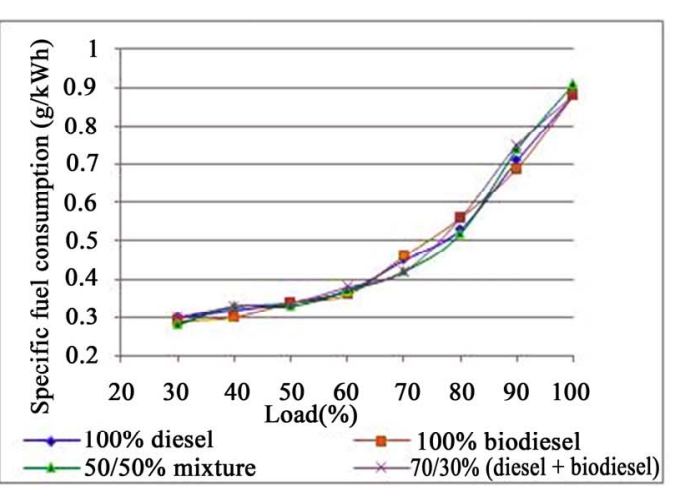

(b)

Figure 3. Specific fuel consumption for range of mixtures at selected compression ratios. (a) Compression ratio 12; (b) Compression ratio 17 .

One of the most discernible trends connected to Figure 1 is that the engine torque improved for all the fuel samples at compression ratio 17 compared with low compression ratio of 12 . Figure 1(b) depicts that as the load increases engine torque increases to the maximum between $50 \%$ and $70 \%$ load then decreases for all the fuel samples. However, compared with the data in Figure 1(a) it can be observed that as the load increases there is significant variations in the engine torque profiles for all the fuel samples with petroleum-based diesel fuel recording relatively high engine torque between $60 \%$ and $70 \%$ load. The data in Figure 1(a) also demonstrates 
that $100 \%$ biodiesel fuel sample recorded relatively low engine torque compared with the rest of the fuel samples. Overally, the results in figure 1 suggest that biodiesel fuel processed by Biodiesel Botswana (Pty) Ltd compares favourably well with petroleum-based diesel fuel used in the Southern African Development Community (SADC) region.

The influence of load and compression ratio on brake power for different fuels is presented in Figure 2. It can be observed from the same figure that as the load increases, brake power increases approximately linearly for all the fuel samples under review.

Comparing the brake power produced by the engine at different loads for different mixtures it is noted that there is little variation between Figures 2(a) and 2(b). The minimum and maximum engine brake power recorded for two selected compression ratios, namely 12 and 17 are approximaly the same. The trends demonstrated in Figure 2 suggest that the quality of biodiesel produced by Biodiesel Botswana (Pty) Ltd compares well with that of petroleum based diesel fuel used in Botswana.

The data in Figure 3 demonstrate trends for specific fuel consumption for all fuels under review.

One of the most discernible trends connected to figure 3 is that the specific fuel consumption for all fuels under review are continuously increasing in similar trends as the engine load increases. The specific fuel consumption for $100 \%$ biodiesel, $50 / 50 \%$ mixture, and $70 / 30 \%$ (diesel.biodiesel mixture) compares favourably well with that of petroleum-based diesel fuel. The authors contend that the trends demonstrated in Figure 3 could be linked to relatively good quality of biodiesel produced by Biodiesel Botswana (Pty) Ltd as echoed earlier in the same section. Overally, the results suggest that biodiesel produced from used cooking oil has the potential to improve energy security in botswana.

\section{Conclusions}

This paper has examined the performance of a single cylinder variable compression ignition engine powered using different fuel mixtures of biodiesel produced from used cooking oil and petroleum diesel. Fuel mixtures consisting of $100 \%$ petroleum-based diesel, $100 \%$ bio- diesel, 50/50\% (diesel/biodiesel) and 70/30\% (diesel/ biodiesel) were tested. The study revealed that the performance of the engine when powered by biodiesel and its blends with petroleum diesel is very comparable to its performance when powered by $100 \%$ petroleum diesel.

\section{Acknowledgements}

Authors acknowledge the manager of Biodiesel Botswana (Pty) Ltd for providing biodiesel fuel.

\section{REFERENCES}

[1] Ministry of Minerals, Energy and Water Resources, "Development of National Biofuel Guidelines,” Government report MTC/MMEWR/EAD/1/4/09-10.

[2] R. L. McCormick, M. S. Graboski, T. L Alleman and A. M. Herring, "Impact of Biodiesel Source Material and Chemical Structure on Emissions of Criteria Pollutants from Heavy-Duty Engine,” Environmental Science \& Technology, Vol. 35, No. 9, 2001, pp. 1742-1747. doi:10.1021/es001636t

[3] C. D. Rakopoulos, D. C Rakopoulos, D. T Hountalas, E. G. Giakoumis and E. C. Andirtsakis, "Performance and Emissions of Bus Engine Using Blends of Diesel Fuel with Bio-diesel of Sunflower or Cottonseed Oils Derived from Greek Feedstock,” Fuel, Vol. 87, No. 2, 2008, pp. 147-157. doi:10.1016/j.fuel.2007.04.011

[4] A. S. Ramadhas, S. Jayaraj and C. Muraleedharan, "Use of Vegetable Oils as I.C. Engine Fuels: A Review,” Renewable Energy, Vol. 29, No. 5, 2004, pp. 727-742. doi:10.1016/j.renene.2003.09.008

[5] European Union, “Directive 2003/30/EC on the Promotion of the Use of Biofuels or Other Renewable Fuels for Transport," Official Journal of the European Union, 2003.

[6] L. F. Bautista, G. Vicente, R. Bodriguez and M. Pacheco, "Optimasation of FAME Production from Waste Cooking Oil for Biodiesel Use,” Biomass and Bioenergy, Vol. 33, No. 5, 2009, pp. 862-872. doi:10.1016/j.biombioe.2009.01.009

[7] Y. Zhang, M. A. Dube, D. D. Mclean and M. Kates, "Biodiesel Production from Waste Cooking Oil 2. Economic Assessment and Sensitivity Analysis," Bioresources Technology, Vol. 90, No. 3, 2003, pp. 229-240. doi:10.1016/S0960-8524(03)00150-0 